\title{
The amazing effects and role of PVP on the crystallinity, phase composition and morphology of nickel ferrite nanoparticles prepared by thermal treatment method
}

\author{
Mahmoud Goodarz Naseri ${ }^{1,2^{*}}$, Elias Saion ${ }^{2}$ and Nasrin Khalil Zadeh ${ }^{2}$
}

\begin{abstract}
Nickel ferrite nanocrystals were prepared from an aqueous solution containing metal nitrates and various concentrations of poly(vinylpyrrolidone) followed by calcination temperature. X-ray diffraction (XRD) analysis was performed to determine the degree of crystallinity of the ferrite nanoparticles. By transmission electron microscopy, the morphology and average particle size of the nickel ferrite nanoparticles were evaluated which had good agreement with the XRD results. Fourier transform infrared spectroscopy suggested the presence of metal oxide bands in all samples as well as the effective elimination of organic constituents after calcinations. Measurements of the extent of magnetization of the nickel ferrite nanoparticles synthesized in different concentrations were obtained at room temperature using a vibrating sample magnetometer.
\end{abstract}

Keywords: Nanostructures, X-ray diffraction, Infrared spectroscopy, Magnetic properties

\section{Background}

The last two decades have seen a significant growth in the study of nanomaterials such as ferrite nanoparticles. The interest in research related to metal spinel ferrite nanoparticles has increased significantly in recent years due to their potential applications in ferrofluids [1], magneto-optics [2], spintronics [3], biomedical applications [4,5], and anodes for batteries [6]. Moreover, they have attracted much attention because of their surface effect (large surface-to-volume ratio) and quantum confinement effects (size-dependent properties). Various fabrication methods have been reported for preparing spinel ferrite nanocrystals for these purposes, e.g., sol-gel methods [7], the ball-milling technique [8], co-precipitation [9], electrospinning method [10], the hydrothermal method [11], the reverse micelles process [12], and the micro-emulsion method [13]. To overcome the drawbacks associated with the

\footnotetext{
* Correspondence: mahmoud.naseri55@gmail.com

${ }^{1}$ Department of Physics, Faculty of Science, Malayer University, Arak Street, Malayer, 65719-95863, Iran

${ }^{2}$ Department of Physics, Faculty of Science, Universiti Putra Malaysia, UPM Street, Serdang, Selangor, 43400, Malaysia
}

abovementioned methods, organic and inorganic capping agents are used to stabilize the particles and prevent them from agglomerating. The properties of ferrite nanoparticles can be altered by controlling their size, which can provide an advantage in formulating new composite materials with optimized properties for various applications. Thus, to control the growth of the spinel ferrite nanoparticles, organic stabilizers (polymers), e.g., polyvinyl alcohol (PVA), polyethylene oxide, polymethacrylic acid, and poly (vinylpyrrolidone) (PVP), are added during the synthesis for capping the surface of the particles $[14,15]$. In our previous work [16], a thermal-treatment method was used to prepare $\left(\mathrm{NiFe}_{2} \mathrm{O}_{4}\right)$ nanoparticles from an aqueous solution that contained metal nitrates, PVP, and deionized water by calcination at various temperatures from 623 to $823 \mathrm{~K}$ (see the "Effect of calcination temperature on the crystallinity, phase composition, morphology, and magnetic properties' subsection). The preparation of the nanoparticles was followed by grinding and calcination. In order to avoid the natural tendency to form aggregates, nickel ferrite nanoparticles were normally prepared or dispersed in PVP matrices. Currently, understanding of the effect of capping nanoparticles is one of the most 
important topics in this area of research. Thus, in this work, the fundamental question that we are attempting to address is how and to what extent the PVP capping agent improves the efficiency of nickel ferrite nanoparticles fabricated by the thermal treatment method. For answers to these questions, nickel ferrite nanocrystals were prepared from an aqueous solution containing metal nitrates and various concentrations of poly(vinylpyrrolidone) followed by calcination temperature. To stabilize the particles, they were thermally treated at $723 \mathrm{~K}$ as an optimum calcination temperature. Prepared nickel ferrite nanoparticles were characterized by different techniques which confirmed that $0.035 \mathrm{~g} / \mathrm{ml}$ of PVP is optimal for the fabrication of the nickel ferrite nanoparticles. Lower than this value, nanoparticles were agglomerated; higher than this value, nanoparticles had impurity.

\section{Methods}

\section{Materials}

Metal nitrate reagents, PVP, and deionized water were used as precursors. In addition, a capping agent to control the agglomeration of the particles and a solvent were used.

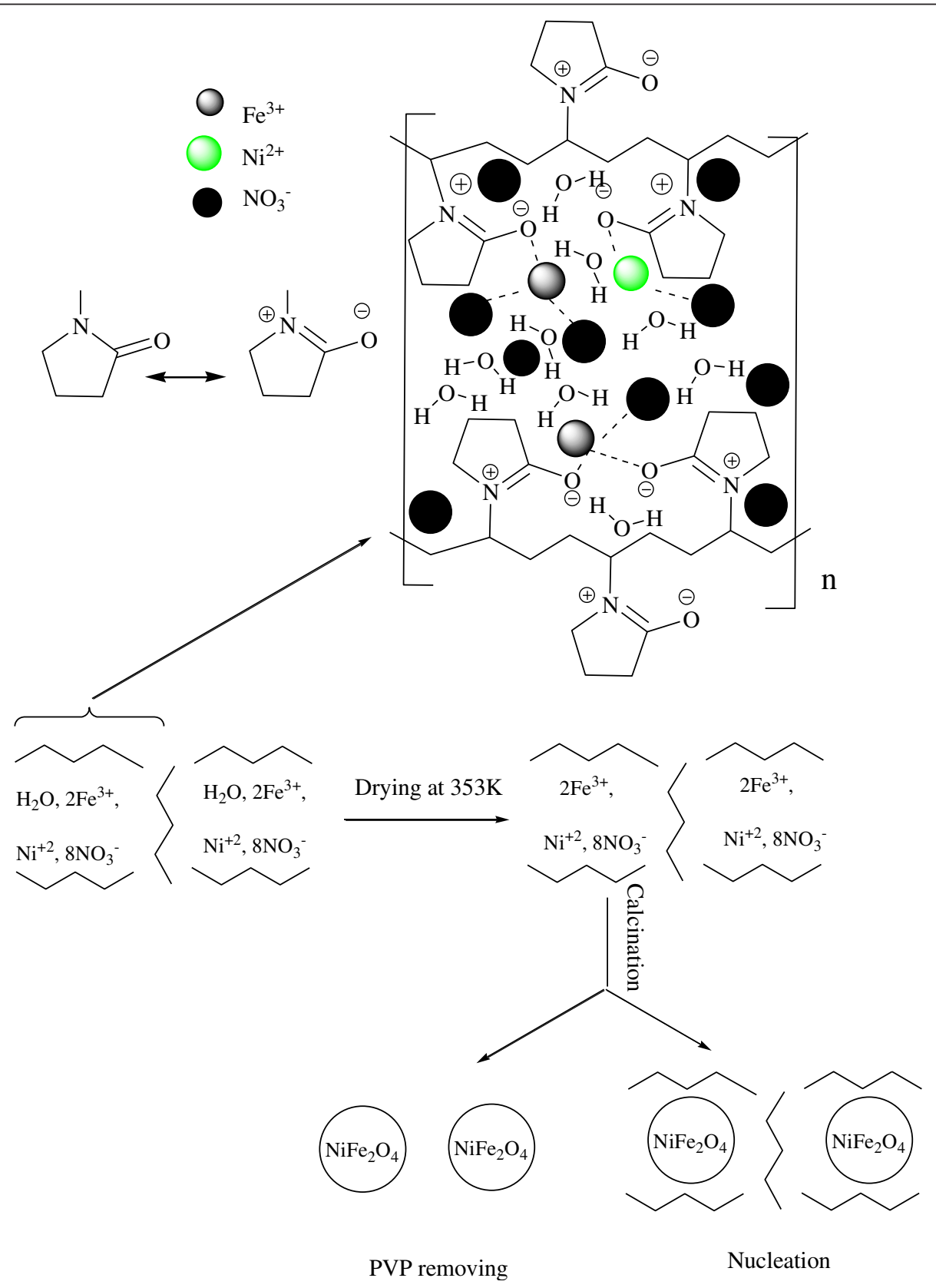

Figure 1 Proposed mechanism of interactions between PVP and metal ions in the formation of nickel ferrite nanoparticles. 
Iron nitrate, $\mathrm{Fe}\left(\mathrm{NO}_{3}\right)_{3} \cdot 9 \mathrm{H}_{2} \mathrm{O}$, and nickel nitrate, $\mathrm{Ni}\left(\mathrm{NO}_{3}\right)$ ${ }_{2} \cdot 6 \mathrm{H}_{2} \mathrm{O}$, were purchased from Acros Organics (NJ, USA) with a purity exceeding 99\%. PVP (MW = 29,000) was purchased from Sigma-Aldrich (St. Louis, MO, USA) and was used without further purification.

\section{Methodology}

In the next set of experiments, we synthesized four separate aqueous solution of PVP which were prepared by dissolving $0,1.5,3.5$, and $5.5 \mathrm{~g}$ of polymer in $100 \mathrm{ml}$ of deionized water at $363 \mathrm{~K}$ before mixing $0.2 \mathrm{mmol}$ of iron nitrate and $0.1 \mathrm{mmol}$ of nickel nitrate $(\mathrm{Fe} / \mathrm{Ni}=2: 1)$ into the polymer solution and constantly stirring for $2 \mathrm{~h}$ using a magnetic stirrer until a colorless, transparent solution was obtained. A glass electrode was used to determine the $\mathrm{pH}$ of the solution, which ranged from 1 to 2 . No precipitation of materials was observed before the heat treatment. The mixed solution was poured into a glass Petri dish and heated at $353 \mathrm{~K}$ in an oven for $24 \mathrm{~h}$ to evaporate the water. The dried, orange, solid nickel ferrite that remained was crushed and ground in a mortar to form powder. The calcination of the powders was conducted at $723 \mathrm{~K}$ for $3 \mathrm{~h}$ for the decomposition of organic compounds and the crystallization of the nanocrystals.

\section{Characterization}

The structure of the $\mathrm{NiFe}_{2} \mathrm{O}_{4}$ nanoparticles was characterized by the X-ray diffraction (XRD) technique using a Shimadzu diffractometer model XRD 6000 (Nakagyo-ku, Kyoto, Japan) employing $\mathrm{Cu} \mathrm{K} \alpha(0.154 \mathrm{~nm})$ radiation to generate diffraction patterns from powder crystalline samples at ambient temperature in a $2 \theta$ range of $10^{\circ}$ to $70^{\circ}$. The microstructure and particle size of the nanocrystals were determined from transmission electron microscopy (TEM) images that were obtained using a JEOL 2010F UHR version electron microscope (Akishima, Tokyo, Japan) at an accelerating voltage of $200 \mathrm{kV}$. Fourier transform infrared (FT-IR) spectra were recorded using a PerkinElmer FT-IR model 1650 spectrometer (Waltham, MA, USA). Before recording the spectra, the samples were placed on a Universal ATR Sampling Accessory (diamond coated with CsI; Perkin Elmer) and pressed and then the spectra were recorded. Magnetization measurements were conducted using a vibrating sample magnetometer (VSM; Lake Shore 4700) at room temperature with maximum magnetic field of $15 \mathrm{kOe}$.

\section{Results and discussion} Mechanism of formation

Interactions between the PVP capping agent [17] and metal ions are shown schematically in Figure 1, which shows that the nickel(II) and iron(III) ions are bound by the strong ionic bonds between the metallic ions and the amide group in a polymeric chain. PVP acts as a stabilizer for dissolved metallic salts through steric and electrostatic stabilization of the amide groups of the pyrolidine rings and the methylene groups. Initially, the PVP stabilizer may decompose to a limited extent, thereby producing shorter polymer chains that are capped when they are adsorbed onto the surfaces of metallic ions [18]. The metallic ions, which are well dispersed in the cavities and networks, are created as a result of the shorter polymer chains. These mechanisms continue until they are terminated by the drying step. The influence of PVP is not restricted only to the solution and the drying

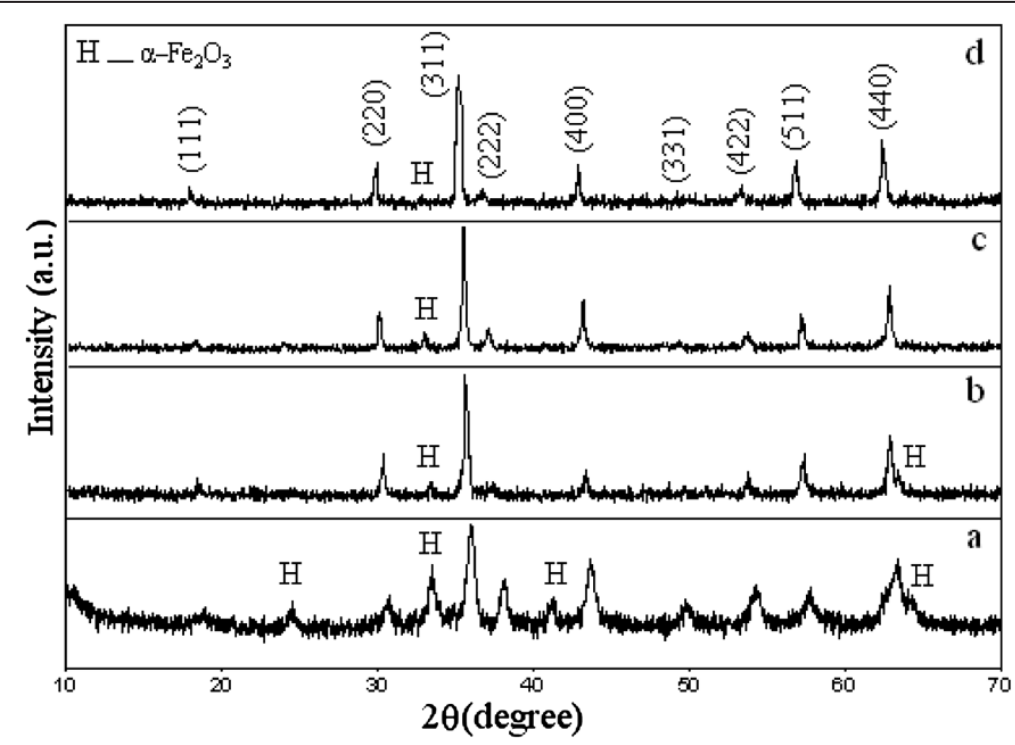

Figure 2 XRD patterns of nickel ferrite nanoparticles. PVP concentrations of (a) 0 , (b) 0.015 , (c) 0.035 , and (d) $0.055 \mathrm{~g} / \mathrm{ml}$ calcined at $723 \mathrm{~K}$. 
Table 1 Phase composition and average particle size $(\mathrm{nm})$ of $\mathrm{NiFe}_{2} \mathrm{O}_{4}$ nanoparticles

\begin{tabular}{cccccc}
\hline $\begin{array}{c}\mathrm{NiFe}_{2} \mathrm{O}_{\mathbf{4}} \\
\text { nanoparticle }\end{array}$ & $\begin{array}{c}\text { Concentration } \\
\text { of PVP }(\mathbf{g} / \mathbf{m l})\end{array}$ & $\begin{array}{c}\text { Percentage of hematite } \\
\text { phase (vol.\%) }\end{array}$ & $\begin{array}{c}\text { Percentage of spinel } \\
\text { phase (vol.\%) }\end{array}$ & $\begin{array}{c}\text { Particle size } \\
\text { by XRD (nm) }\end{array}$ & $\begin{array}{c}\text { Particle size } \\
\text { by TEM (nm) }\end{array}$ \\
\hline 1 & 0 & 26.2 & 73.8 & - & - \\
\hline 2 & 0.015 & 6.1 & 93.9 & 11 & 9 \\
\hline 3 & 0.035 & 2.1 & 97.9 & 15 & 12 \\
\hline 4 & 0.055 & 1.7 & 98.3 & 16 \\
\hline
\end{tabular}

Various concentrations of PVP determined by XRD and TEM techniques and calcined at $723 \mathrm{~K}$.

step; PVP also affects the formation of the nuclei (i.e., nucleation) of the nickel ferrite nanoparticles in the calcination step. In this step, the small nanoparticles with high surface energy levels would become larger via the Ostwald ripening process [19] without the presence of PVP, which disrupts steric hindrance, thereby preventing their aggregation. Steric hindrance is a phenomenon that is attributed to large molecular weight $(>10,000)$ and the repulsive forces acting among the polyvinyl groups $[20,21]$. These interactions are similar to the stabilization of metallic nanoparticles, i.e., silver and gold [22,23].

\section{Effect of calcinations temperature on the crystallinity,} phase composition, morphology and magnetic properties In this subsection, we briefly report the results of our previous work [16] that the authors investigated on the effect of calcination temperature on the crystallinity, phase composition, morphology, and magnetic properties of nickel ferrite nanoparticles. When the precursor of nickel ferrite nanoparticles was calcined at 623, 673, 723 , and $823 \mathrm{~K}$, the particle sizes of nickel ferrite nanoparticles increased to 7, 9, 12, and $47 \mathrm{~nm}$, respectively, as confirmed by TEM and XRD analyses. A completed crystallization occurred at 723 and $823 \mathrm{~K}$, as was conducted by the absence of organic absorption bands in the FT-IR spectrum. The magnetic studies showed that the saturation magnetization $\left(M_{\mathrm{s}}\right)$ of the nickel ferrite nanoparticles increased as the temperature increased while the coercivity field $\left(H_{\mathrm{c}}\right)$ increased, until they achieved a maximum value and then decreased. Optimum calcination temperature of nickel ferrite nanoparticles occurred at $723 \mathrm{~K}$ because this temperature was the minimum temperature at which the nanoparticles were pure; also, this was the temperature at which the
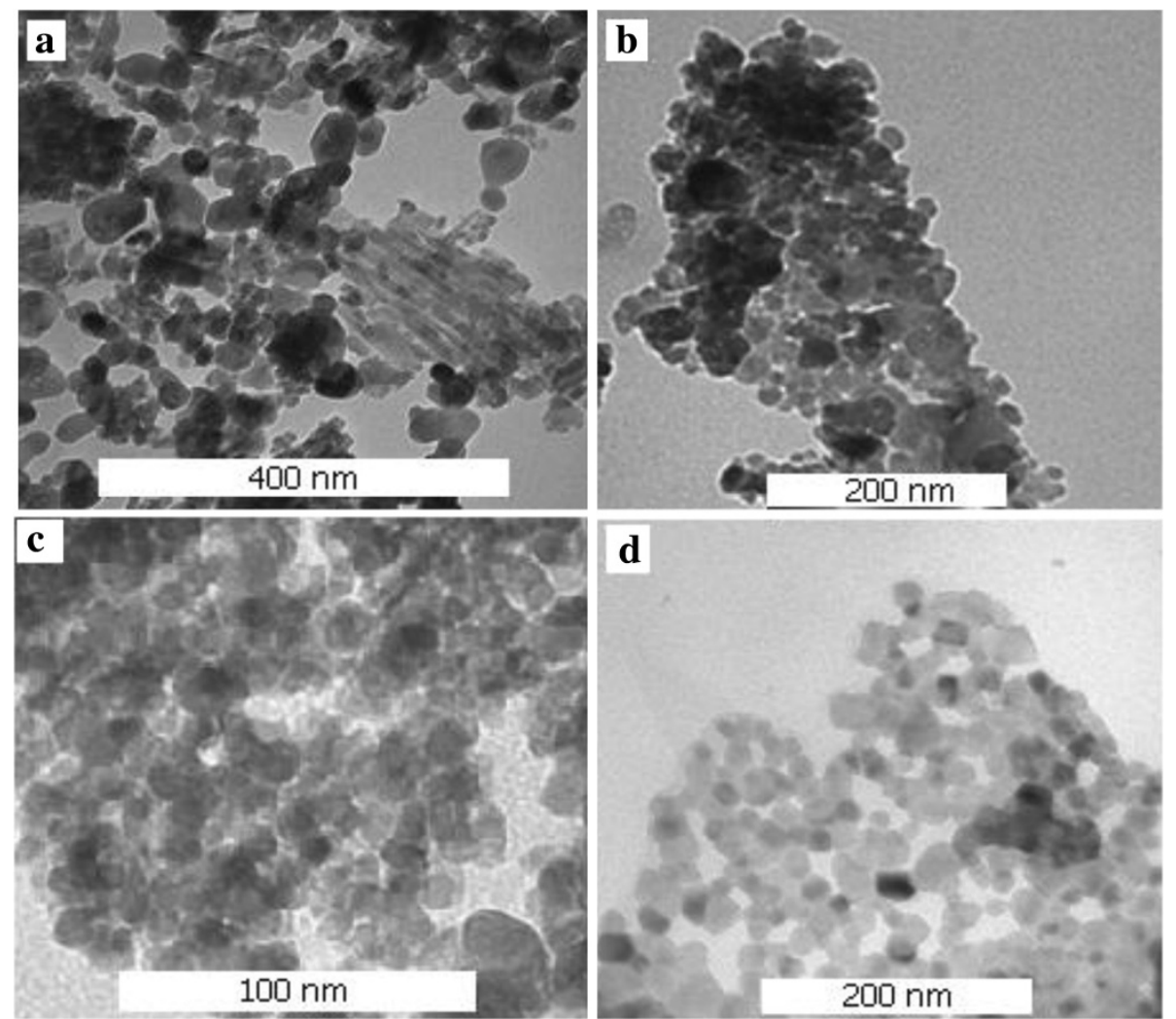

Figure 3 TEM images of nickel ferrite nanoparticles. PVP concentrations of (a) 0 , (b) 0.015 , (c) 0.035 , and (d) $0.055 \mathrm{~g} / \mathrm{ml}$ calcined at $723 \mathrm{~K}$. 
nanoparticles had the smallest particle size and a nearly uniform distribution of shapes.

Effect of concentration of PVP on the crystallinity, phase composition, morphology and magnetic properties

Figure 2 shows the XRD peaks of nickel ferrite nanoparticles that were prepared with concentrations of PVP ranging from 0 to $0.055 \mathrm{~g} / \mathrm{ml}$ and calcined at $723 \mathrm{~K}$. It is important to note that, in thermal treatment method, the optimum temperature for the calcination of nickel ferrite nanoparticles was $723 \mathrm{~K}$ because this temperature was the minimum temperature at which the nanoparticles were pure; also, this was the temperature at which the nanoparticles had the smallest particle size and a nearly uniform distribution of shapes [16]. It is evident from Figure 2 that the patterns show the reflection planes (111), (220), (311), (222), (400), (331), (422), (511), and (440), which confirm the presence of singlephase $\mathrm{NiFe}_{2} \mathrm{O}_{4}$ with a face-centered cubic structure [24]. Except for the impure phase of $\alpha-\mathrm{Fe}_{2} \mathrm{O}_{3}$, which is found in all calcined samples and occurs naturally as hematite [25], the remaining peaks correspond to the standard pattern of $\mathrm{NiFe}_{2} \mathrm{O}_{4}$ (cubic, $a=0.8339 \mathrm{~nm}$, space group: Fd3m, $Z=8$; ICDD PDF: 44-1485).

Table 1 shows the percentages of hematite phase $\left(\alpha-\mathrm{Fe}_{2} \mathrm{O}_{3}\right)$ and spinel phase $\left(\mathrm{NiFe}_{2} \mathrm{O}_{4}\right)$ of samples with various concentrations from 0 to $0.055 \mathrm{~g} / \mathrm{ml}$ which were estimated by X'Pert HighScore software. The highest percentage of hematite phase (29.3 vol.\%) and the lowest percentage of spinel phase (70.7 vol.\%) occurred in the absence of PVP, but when the concentration of PVP increased from 0.015 to $0.055 \mathrm{~g} / \mathrm{ml}$, the percentage of hematite phase decreased from 5.1 to 1.9 vol.\% while spinel phase increased from 94.9 to 98.1 vol.\%. This confirmed that the presence of PVP significantly improved the percentage of spinel phase or the degree of crystallinity of these products.

The average particle size was determined from the full-width at half maximum of the XRD patterns, using the well-known Scherer formula:

$$
D=0.9 \lambda / \beta \cos \theta
$$

where $D$ is the crystallite size $(\mathrm{nm}) ; \beta$, the full width of the diffraction line at half of the maximum intensity measured in radians; $\lambda$, the X-ray wavelength of $\mathrm{Cu} \mathrm{K \alpha}=$ $0.154 \mathrm{~nm}$; and $\theta$, the Bragg angle [26]. The particle sizes estimated using the Scherer formula were found to increase with the concentration of PVP from 0.015 to $0.055 \mathrm{~g} / \mathrm{ml}$ as shown in Table 1 .

A comparison of XRD peaks shows that either the numbers or the intensities of the unwanted peaks of $\alpha-\mathrm{Fe}_{2} \mathrm{O}_{3}$ increase in the absence of PVP, but when PVP is present at concentrations of $0.015,0.035$, and 0.055 $\mathrm{g} / \mathrm{ml}$, either some of the unwanted peaks of $\alpha-\mathrm{Fe}_{2} \mathrm{O}_{3}$ were removed or some of their intensities were decreased. This could be due to the fact that decreasing the concentration of PVP results in increases in the concentrations of nickel and iron ions [27]. In fact, due to the absence of PVP, there is no interaction between ions and PVP chains, which resulted in increasing either the numbers or the intensities of the unwanted peaks of $\alpha-\mathrm{Fe}_{2} \mathrm{O}_{3}$ [28]. Therefore, one of the important roles of PVP in the synthesis of nickel ferrite nanoparticles by the thermal treatment method is the enhancement of

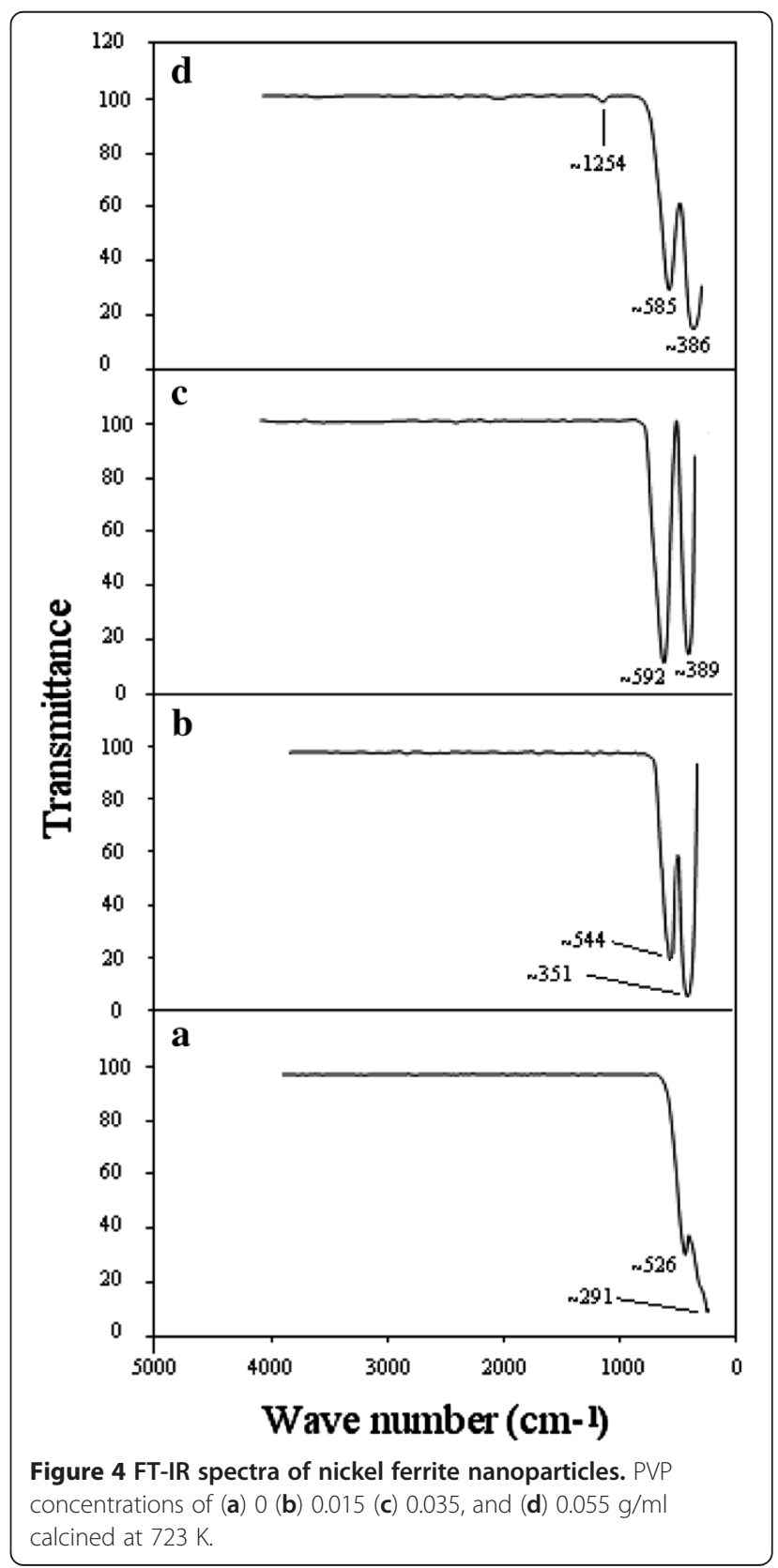




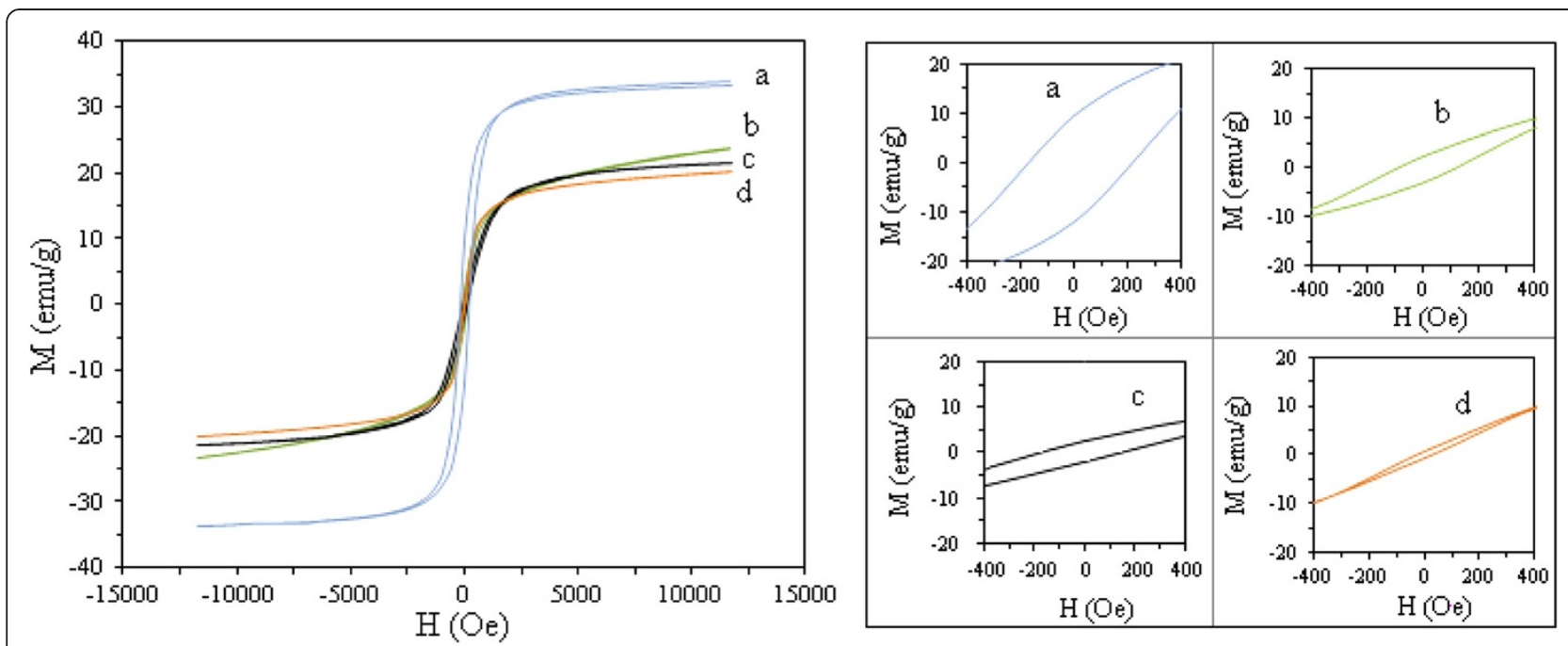

Figure 5 Magnetization curves of nickel ferrite nanoparticles. Various concentrations of PVP from (a) 0 , (b) 0.015 , (c) 0.035, to (d) $0.055 \mathrm{~g} / \mathrm{ml}$ at room temperature and calcined at $723 \mathrm{~K}$.

the degree of the crystallinity by decreasing or removing $\alpha-\mathrm{Fe}_{2} \mathrm{O}_{3}$.

These results are in good agreement with the work by Anuchit et al. using PVA as starting materials for sol-gel synthesis of $\mathrm{CoFe}_{2} \mathrm{O}_{4}$ nanoparticles [29]. Their results suggested that the addition of PVA improved the crystallinity of $\mathrm{CoFe}_{2} \mathrm{O}_{4}$ nanoparticles and, in its absence, the $\mathrm{Fe}_{2} \mathrm{O}_{3}$ may be formed.

To further investigate the role of PVP in the synthesis of nickel ferrite nanoparticles, we have shown the TEM images and the FT-IR spectra of nickel ferrite nanoparticles with various concentrations of $0,0.015,0.035$, and $0.055 \mathrm{~g} / \mathrm{ml}$ (Figures 3 and 4). Figure 3a shows that nickel ferrite nanoparticles were formed even in the absence of PVP. However, in this case, it was observed that the nanoparticles did not have a uniform distribution of shapes, and they were aggregated extensively and, in some areas, completely disproportionately distributed. Thus, without the use of PVP in the synthesis of nanoparticles, the small nanoparticles aggregate and produce larger nanoparticles [21] due to high surface energy (as shown earlier in Figure 1). When the concentration of PVP was increased to $0.015 \mathrm{~g} / \mathrm{ml}$, the nickel ferrite nanoparticles that were formed with an average size of $9 \mathrm{~nm}$ became more regular in shape than in the case without PVP (Figure 3b). However, due to the low concentration of PVP, these nanoparticles also aggregated because there was insufficient PVP to cap them well and prevent their agglomeration. By increasing the PVP concentration to $0.055 \mathrm{~g} / \mathrm{ml}$, the nickel ferrite nanoparticles did not agglomerate, and they were nearly uniform in shape, as shown in Figure 3d. However, in this case, the nickel ferrite nanoparticles ranged in size from 9 to $21 \mathrm{~nm}$, with an estimated average particle size of approximately $13 \mathrm{~nm}$. These results were similar to the results achieved when a PVP concentration of $0.035 \mathrm{~g} / \mathrm{ml}$ was used (shown in Figure 3c).

Two main broad metal-oxygen bands are seen in Figure 4 in the IR spectra of all spinel ferrite nanoparticles, which correspond to intrinsic stretching vibrations of the metal at the tetrahedral site, $\mathrm{M}_{\text {tetra }} \leftrightarrow \mathrm{O}$ (observed from 526 to $592 \mathrm{~cm}^{-1}$ ) and octahedral metal stretching, $\mathrm{M}_{\text {octa }} \leftrightarrow \mathrm{O}$ (observed from 291 to $389 \mathrm{~cm}^{-1}$ ) [30]. However, due to the high concentration of PVP, traces of organic materials were observed at $1,254 \mathrm{~cm}^{-1}$, which was attributed to the $\mathrm{C}-\mathrm{H}$ bending vibration of methylene groups [31], as shown in Figure 4d. In fact, it is apparent that the nickel ferrite nanoparticles were contaminated with organic compounds in this case. However, in the absence of PVP and with the concentrations of less than $0.055 \mathrm{~g} / \mathrm{ml}$, the fabricated nickel ferrite nanoparticles were pure as shown in Figure 4a,b,c. Therefore, in the thermal treatment method, the optimum concentration of PVP for the synthesis of nickel ferrite nanoparticles is $0.035 \mathrm{~g} / \mathrm{ml}$. That concentration, in combination with the optimum temperature $(723 \mathrm{~K})$, provided the conditions required to fabricate pure nickel ferrite nanoparticles that have the smallest particle size.

Table 2 Magnetic properties of $\mathrm{NiFe}_{2} \mathrm{O}_{4}$ nanoparticles

\begin{tabular}{cccc}
\hline $\begin{array}{c}\mathrm{NiFe}_{\mathbf{2}} \mathrm{O}_{\mathbf{4}} \\
\text { nanoparticle }\end{array}$ & $\begin{array}{c}\text { Concentration } \\
\text { of PVP }(\mathbf{g} / \mathbf{m l})\end{array}$ & $\boldsymbol{M}_{\mathbf{s}}$ (emu/g) & $\boldsymbol{H}_{\mathbf{c}}(\mathbf{O e})$ \\
\hline 1 & 0 & 33.25 & $208(-194)$ \\
\hline 2 & 0.015 & 23.87 & $154(-121)$ \\
\hline 3 & 0.035 & 21.37 & $150(-148)$ \\
\hline 4 & 0.055 & 20.16 & $28(-27)$ \\
\hline
\end{tabular}

Various concentrations of PVP determined by VSM technique at room temperature and calcined at $723 \mathrm{~K}$. 
Finally, we report the magnetization curves of nickel ferrite nanoparticles with various concentrations of PVP from $0,0.015,0.03$, to $0.055 \mathrm{~g} / \mathrm{ml}$ that were measured at room temperature in the range of approximately -15 to $+15 \mathrm{kOe}$, which exhibited typical magnetic behaviors (shown in Figure 5). It is evident in Table 2 that, when the concentrations of PVP increase from 0 to $0.055 \mathrm{~g} / \mathrm{ml}$, the saturation magnetization decreases from 32.45 to $20.77 \mathrm{emu} / \mathrm{g}$ at room temperature. The decrease in saturation magnetization of all the samples compared to that of the bulk nickel ferrite $(55 \mathrm{emu} / \mathrm{g})$ [32] depends on different parameters. In the thermal treatment method, the heating rate of calcination is one of the most important parameters that can effectively increase or decrease the saturation magnetization.

In this investigation, the heating rate of calcination was $10 \mathrm{~K} / \mathrm{min}$ for nickel ferrite nanoparticles which was a relatively high heating rate. Therefore, it is possible that calcination at a slower heating rate would allow crystallization to be more complete and the magnetic phase could also increase, resulting in larger saturation magnetization [16].

The variation in the value of the saturation magnetization with particle size may have resulted from the cation redistribution (interchanging of $\mathrm{Ni}$ and $\mathrm{Fe}$ ions of the tetrahedral and octahedral sites). This cation redistribution causes the structure of $\mathrm{NiFe}_{2} \mathrm{O}_{4}$ to change from an inverse spinel to a mixed spinel [33]. Furthermore, the surface is likely to behave as an inactive and dead layer with inconsiderable magnetization [34].

By increasing the amount of PVP, the coercivity field increased from 28 to 190 Oe as listed in Table 2. This difference in magnetic behavior can be related to the phase difference in ferrite products [29]. Moreover, the variation in the value of the coercivity field with particle size can be explained on the basis of domain structure, critical size, and the anisotropy of the crystal [35].

\section{Conclusion}

This work investigated a comprehensive research on the amazing effects and role of PVP in the synthesis of nickel ferrite nanoparticles by the thermal treatment method. Briefly, as was discussed when we considered our XRD results, TEM images, FT-IR spectra, and VSM results, PVP plays five crucial roles in synthesizing zinc ferrite nanoparticles, i.e., (1) the control of the growth of nanoparticles, (2) the prevention of agglomeration of nanoparticles, (3) the enhancement of the degree of the crystallinity of nanoparticles, (4) the production of nanoparticles that have a uniform distribution of shapes, and (5) by increasing the amount of PVP, the saturation magnetization decreased while the coercivity field increased. Optimum concentration of PVP $(0.040 \mathrm{~g} / \mathrm{ml})$ was obtained because of the fact that this concentration was the minimum concentration at which the nanoparticles were pure; also, this was the concentration at which the nanoparticles had the smallest particle size and a nearly uniform distribution of shapes.

\section{Competing interests}

The authors declare that they have no competing interests.

\section{Authors' contributions}

MGN is a postdoctoral student who performed the experiment and prepared the manuscript. ES supervised in conducting this work. NKZ is a doctoral student who studied on nanostructures. All authors read and approved the final manuscript.

\section{Authors' information}

MGN received his B.Sc. degree in Physics in 2001 from the Department of Physics, University of Isfahan, Iran, M.Sc. degree in 2006 from the Department of Physics, Tehran University of Teacher Training, Iran, and Ph.D. in 2012 from the University of Putra Malaysia. He is currently working on nanoscience and nanotechnology in his postdoctoral session in the University of Putra Malaysia. His research interest includes the effects and role of PVP on the crystallinity, phase composition, and morphology of nickel ferrite nanoparticles prepared by thermal treatment method. ES is a professor of Radiation Biophysics in the Department of Physics, University of Putra Malaysia. He received his master's degree in Medical Physics in 1978 from the University of Surrey, England and his Ph.D. in 1989 from the University of St. Andrews, Scotland. His current research interest include synthesis and characterization of metal nanoparticles, quantum dots, and various conducting organic polymer dots by thermal and radiation methods, quantum mechanical calculation of metal nanoparticles and semiconductor, quantum dots based on density functional theory, radiation treatment of ionic membranes, elemental assessments using INAA and ICPAMS, and diagnostic and radiotherapy treatment planning. He has several publications in peer-reviewed international journals. NKZ received B.Sc. and M.Sc. degrees in Iran, and is currently attending Ph.D. session on nanostructures in the University of Putra Malaysia.

\section{Acknowledgments}

This work was supported by the Ministry of Higher Education of Malaysia and Malayer University of Iran under the FRGS grant and Universiti Putra Malaysia under the RUGS grant.

Received: 8 April 2012 Accepted: 26 February 2013

Published: 8 April 2013

\section{References}

1. Rosesweig, RE: Ferrohydrodynamics. Dover, New York, USA (1985)

2. Tirosh, E, Shemer, G, Markovich, G: Optimizing cobalt ferrite nanocrystal synthesis using a magneto-optical probe. Chem. Mater. 18, 465-470 (2006)

3. Luders, U, Barthelemy, A, Bibes, M, Bouzehouane, K, Fusil, S, Jacquet, E, Contour, JP, Bobo, JF, Fontcuberta, J, Fert, A: $\mathrm{NiFe}_{2} \mathrm{O}_{4}$ : a versatile spinel material brings new opportunities for spintronics. Adv. Mater. 18, 1733-1736 (2006)

4. Pankhurst, QA, Connolly, J, Jones, SK, Dobson, J: Applications of magnetic nanoparticles in biomedicine. J. Phys. D: Appl. Phys. 36, R167-R181 (2003)

5. Berry, CC: Possible exploitation of magnetic nanoparticle-cell interaction for biomedical applications. J. Mater. Chem. 15, 543-547 (2005)

6. Selvan, RK, Kalaiselvi, N, Augustin, $\mathrm{CO}, \mathrm{Doh}, \mathrm{CH}$ : An approach to enhance the electrochemical properties of nanocrystalline $\mathrm{CuFe}_{2} \mathrm{O}_{4}$ for lithium-ion batteries. Electrochem Solid State Lett. 9, A390-A394 (2006)

7. Atif, M, Hasanain, SK, Nadeem, M: Magnetization of sol-gel prepared zinc ferrite nanoparticles: effects of inversion and particle size. Solid State Communication 138, 416-421 (2006)

8. Jiang, JZ, Wynn, P, Morup, S, Okada, T, Berry, FJ: Magnetic structure evolution in mechanically milled nanostructured ZnFe2O4 particles. Nanostruct. Mater. 12, 737-740 (1999)

9. Shenoy, SD, Joy, PA, Anantharaman, MR: Effect of mechanical milling on the structural, magnetic and dielectric properties of coprecipitated ultrafine zinc ferrite. J. Magn. Magn. Mater. 269, 217-226 (2004) 
10. Ponhan, W, Maensiri, S: Fabrication and magnetic properties of electrospun copper ferrite $\left(\mathrm{CuFe}_{2} \mathrm{O}_{4}\right)$ nanofibers. Solid State Sci. 11, 479-484 (2009)

11. Yu, SH, Fujino, T, Yoshimura, M: Hydrothermal synthesis of ZnFe2O4 ultrafine particles with high magnetization. J. Magn. Magn. Mater. 256, 420-424 (2003)

12. Morrison, SA, Cahill, CL, Carpenter, EE, Calvin, S, Swaminathan, R, McHenry, ME, Harris, VG: Magnetic and structural properties of nickel zinc ferrite nanoparticles synthesized at room temperature. J. Appl. Phys. 95, 6392-6395 (2004)

13. Hochepied, JF, Bonville, P, Pileni, MP: Nonstoichiometric zinc ferrite nanocrystals: syntheses and unusual magnetic properties. J. Phys. Chem. B 104, 905-912 (2000)

14. Naseri, MG, Saion, EB, Ahangar, AH, Shaari, HA: Fabrication, characterization, and magnetic properties of copper ferrite nanoparticles prepared by a simple, thermal-treatment method. Mater. Res. Bull. 48, 1439-1446 (2013)

15. Naseri, MG, Saion, EB, Hashim, M, Shaari, AH, Ahangar, HA: Synthesis and characterization of zinc ferrite nanoparticles by a thermal treatment method. Solid State Commun. 151, 1031-1035 (2011)

16. Naseri, MG, Saion, EB, Ahangar, HA, Hashim, M, Shaari, AH: Simple preparation and characterization of nickel ferrite nanocrystals by a thermal treatment method. Powder Technol. 212, 80-88 (2011)

17. Sivakumar, P, Ramesh, R, Ramanand, A, Ponnusamy, S, Muthamizhchelvan, C: Synthesis and characterization of $\mathrm{NiFe}_{2} \mathrm{O}_{4}$ nanosheet via polymer assisted co-precipitation method. Mater. Lett. 65, 483-485 (2011)

18. Koebel, MM, Jones, LC, Somorjai, GA: Preparation of size-tunable, highly monodisperse PVP-protected Pt-nanoparticles by seed-mediated growth. J Nanopart Res. 10, 1063-1069 (2008)

19. Roosen, AR, Carter, WC: Simulations of microstructural evolution: anisotropic growth and coarsening. Physica A. 261, 232-247 (1998)

20. Ghosh, G, Naskar, MK, Patra, A, Chatterjee, M: Synthesis and characterization of PVP-encapsulated ZnS nanoparticles. Opt. Mater. 28, 1047-1053 (2006)

21. Shao, H, Huang, $Y$, Lee, $H$, Suh, YJ, Kim, CO: Effect of PVP on the morphology of cobalt nanoparticles prepared by thermal decomposition of cobalt acetate. Curr Appl Phy. 6(S1), e195-e197 (2006)

22. Wen-yao, H, Guo-cai, X: Characterization of nano-Ag/PVP composites synthesized via ultra-violet irradiation. J. Coal SciEng. 16, 188-192 (2010)

23. Tsuji, M, Hashimoto, M, Nishizawa, Y, Tsuji, T: Synthesis of gold nanorods and nanowires by microwave-polyol method. Mater. Lett. 58, 2326-2330 (2004)

24. Singh, JP, Srivastava, RC, Agrawal, HM, Kushwaha, RPS: ${ }^{57}$ Fe Mössbauer spectroscopic study of nanostructured zinc ferrite. J. Hyperfine Interact. 183, 393-400 (2009)

25. Laokul, P, Amornkitbamrung, V, Seraphin, S, Maensiri, S: Characterization and magnetic properties of nanocrystalline $\mathrm{CuFe}_{2} \mathrm{O}_{4}, \mathrm{NiFe}_{2} \mathrm{O}_{4}, \mathrm{ZnFe}_{2} \mathrm{O}_{4}$ powders prepared by the Aloe vera extract solution. Curr Appl Phy. 11, 101-108 (2011)

26. Cullity, BD: Elements of X-ray Diffraction, 2nd edn. Addison-Wesley, London (1978)

27. Sharma, DR, Mathur, R, Vadera, SR, Kumar, N, Kutty, TRN: Synthesis of nanocomposites of $\mathrm{Ni}-\mathrm{Zn}$ ferrite in aniline formaldehyde copolymer and studies on their pyrolysis products. J. Alloys Compd. 358, 193-204 (2003)

28. Elsayed, AH, Mohy Eldin, MS, Elsyed, AM, Younes, EM, Motaweh, HA, Abo Elazm, AH: Synthesis and properties of polyaniline/ferrites nanocomposites. Int. J. Electrochem. Sci 6, 206 (2011)

29. Hunyek, A, Sirisathitkul, C, Harding, P: Formation of cobalt ferrites from aqueous solutions of metal nitrates containing PVA: effects of the amount of PVA and annealing temperature. J. Ceram. Soc. Jpn. 119, 541 (2011)

30. Niasari, MS, Davar, F, Mahmoudi, T: A simple route to synthesize nanocrystalline nickel ferrite $\left(\mathrm{NiFe}_{2} \mathrm{O}_{4}\right)$ in the presence of octanoic acid as a surfactant. Polyhedron. 28, 1455-1458 (2009)

31. Nyutu, EK, Conner, WC, Auerbach, SM, Chen, CH, Suib, SL: Ultrasonic nozzle spray in situ mixing and microwave-assisted preparation of nanocrystalline spinel metal oxides: nickel ferrite and zinc aluminate. J. Phys. Chem. $112,1407-1414$ (2008)

32. Smit, J, Wijn, HPJ: Ferrites_Physical Properties of Ferromagnetic Oxides in Relation to Their Technical Applications. Wiley, New York (1959)

33. Jacob, J, Abdul Khadar, M: Investigation of mixed spinel structure of nanostructured nickel ferrite. J. Appl. Phys. 107, 114310 (2010)
34. Maaz, K, Karim, S, Mumtaz, A, Hasanain, SK, Liu, J, Duan, JL: Synthesis and magnetic characterization of nickel ferrite nanoparticles prepared by co-precipitation route. J. Magn. Magn. Mater. 321, 1838-1842 (2009)

35. Vasic, MV, Antic, B, Kremenovic, A, Nikolic, AS, Stoiljkovic, M, Bibic, N, Spasojević, V, Colomban, P: Particle size and strain analysis, structural, magnetic and Raman studies of nanocomposite $\mathrm{Zn} \mathrm{Ni}$ ferrite/NiO nanocomposite powder obtained from acetylacetonato complexes. Nanotechnol 17, 4877-4884 (2006)

doi:10.1186/2228-5326-3-19

Cite this article as: Goodarz Naseri et al:: The amazing effects and role of PVP on the crystallinity, phase composition and morphology of nickel ferrite nanoparticles prepared by thermal treatment method. International Nano Letters 2013 3:19.

\section{Submit your manuscript to a SpringerOpen ${ }^{\odot}$ journal and benefit from:}

- Convenient online submission

Rigorous peer review

- Immediate publication on acceptance

- Open access: articles freely available online

- High visibility within the field

- Retaining the copyright to your article

Submit your next manuscript at $>$ springeropen.com 